\title{
Hipermídia para aprendizagem da língua espanhola: avaliação qualitativa realizada por usuários/tutores
}

\author{
Hypermedia for learning the Spanish language: qualitative assessment performed by \\ users / tutors
}

\author{
Juliane Vargas Nunes, Berenice Santos Gonçalves
}

\begin{abstract}
Design de Hipermídia, avaliação de usabilidade, projeto centrado no usuário, interação.
O tutor de EAD atua como mediador do processo de aprendizagem a distância. Buscando afirmar esse papel, este artigo apresenta uma avaliação qualitativa relativa ao processo de interação entre usuários/tutores e uma hipermídia para aprendizagem no contexto da EAD. Após a fundamentação teórica, adotou-se o método prospectivo de entrevistas realizadas com tutores presenciais e a distância atuantes em um curso de Letras Espanhol da UAB. As perguntas realizadas nas entrevistas foram originadas por categorias investigação prédefinidas a partir dos seguintes eixos: explicitação dos objetivos de aprendizagem, clareza na apresentação dos conceitos/conteúdos, uso dos recursos midiáticos, legibilidade e consistência na apresentação visual das telas, dentre outros. Tais eixos, também foram utilizados na categorização dos dados levantados. Alguns dos resultados ressaltam a importância da mediação do tutor na reiteração dos objetivos de aprendizagem, a necessidade de manutenção do menu em todas as telas da hipermídia e a inserção de ferramentas de busca. Tal avaliação pretende contribuir com novos projetos no contexto do curso.
\end{abstract}

Hypermedia Design, usability evaluation, user-centered design, interaction.

The e-learning tutor acts as mediator of the distance learning process. Seeking to assert this role, this paper presents a qualitative assessment on the process of interaction between users/tutors and hypermedia for learning in the context of e-learning. After the theoretical foundation adopted the prospective method of interviews with tutors working on a course in Spanish Literature from UAB. The questions asked in the interviews were caused by pre-defined categories investigation from the following areas: clarification of learning objectives, clarity of presentation of concepts / content, use of media resources, readability and consistency in the presentation of visual displays, among others. Such axes were also used in the categorization of the data collected. Some of the results were related to the importance of mediation in tutor reiteration of the learning objectives, the need to maintain the menu on all screens and insertion of hypermedia search engines. This review aims to contribute with new projects in the context of the course.

\section{Introdução}

O Design de Hipermídia é uma área de conhecimento com foco na elaboração de artefatos digitais com qualidades hipermidiáticas. Lima-Marques e Cavalcanti (2009) definem a hipermídia como o resultado da fusão entre a multimídia - a utilização simultânea de diversas mídias - e o hipertexto - um sistema que permite o estabelecimento de associações entre diferentes partes de um mesmo texto, a partir da interação do usuário. Santaella (2004) aponta pelo menos quatro traços definidores da hipermídia: hibridização de linguagens, organização reticular dos fluxos informacionais, flexibilidade e não linearidade; e interatividade.

Por suas qualidades específicas, a hipermídia têm sido amplamente utilizada no contexto educativo, sobretudo à distância. A hipermídia permite relacionar assuntos diversos de maneira interconectada, possibilitando ao aluno se aprofundar em diversos níveis de um determinado conhecimento, de acordo com seu interesse e ritmo de aprendizagem (FLOR et al, 2008). Além disso, a integração de diferentes linguagens ou mídias possibilita a exploração de diversos sentidos, ampliando as formas de aproximação entre o aluno e o conteúdo; assim como gera certo grau de redundância, situação necessária ao ato cognitivo. 
Contudo, para que alcance seus objetivos de aprendizagem é importante que a hipermídia esteja adequada às necessidades e características de seus usuários. Um projeto de hipermídia centrado no usuário ${ }^{1}$ exige que a organização das informações obedeça a uma lógica de utilização que respeite a experiência do usuário, quer seja em relação ao domínio tratado, quer seja em relação ao conhecimento prévio em informática. "Conhecer o usuário agrega facilidades tanto na prospecção de informações quanto no seu direcionamento" (ULBRICHT et al, 2008:3).

No contexto da educação a distância, onde alunos e professores estão fisicamente distantes, a mediação de ensino é realizada, sobretudo, por tutores presenciais e a distância ${ }^{2}$. Segundo o MEC (2010), os tutores desempenham um papel fundamental dentro do processo educativo da $\mathrm{EaD}$ e devem ser compreendidos como sujeitos com participação ativa da prática pedagógica. Dessa forma, o domínio do conteúdo é imprescindível tanto para tutores a distância quanto presenciais e representa uma condição essencial para o exercício de suas funções.

A partir de tal perspectiva, este artigo apresenta uma avaliação sobre a qualidade de interação entre usuários/tutores do curso de Licenciatura em Letras-Espanhol na modalidade a distância UFSC e a hipermídia Acércate al Diccionario. Dentre os aspectos investigados têm-se explicitação dos objetivos de aprendizagem, clareza na apresentação dos conceitos/conteúdos, uso dos recursos midiáticos, legibilidade, consistência na apresentação visual das telas, dentre outros. Com tal avaliação objetiva-se apontar características específicas que possam contribuir com novos projetos no contexto do curso.

\section{Projeto de hipermídia}

Há alguns anos, a produção de sistemas hipermidiáticos era executada por apenas dois ou três diferentes profissionais, como o especialista no conteúdo e o especialista em programação (ULBRICHT et al (2008). A concepção atual é de que essa tarefa deve ser executada por uma equipe específica, composta por profissionais de diferentes áreas como designers, especialistas em tratamento de imagens estáticas, especialistas em animação, especialistas em produção de vídeo e áudio, especialistas no público alvo, programador, engenheiros do conhecimento, etc. Essa tendência de composição de equipe multidisciplinar fez com que designers da informação e de interface ganhassem maior visibilidade.

A constituição desta equipe deve ser norteada pelas especificidades e objetivos da hipermídia. O que se objetiva, é que cada um desses profissionais contribua com seus diferentes conhecimentos e habilidades para um objetivo comum. Em função das diferentes características de cada um desses profissionais, é imprescindível que se faça um bom planejamento do processo de elaboração da hipermídia, explicitando para os participantes todas as etapas e diretrizes do projeto e mantendo-os em constante diálogo (ULBRICHT et al, 2008).

\section{Interação e navegação}

Segundo Padovani (2008), interação refere-se ao processo de comunicação estabelecido entre o usuário e o sistema, durante a realização de tarefas; enquanto interatividade consiste em uma característica variável que se refere ao quão pró-ativo a configuração do sistema permite que o usuário seja durante a interação, podendo ser medida em níveis. Assim, como enfatiza Filatro (2008), a interatividade mostra-se como um pré-requisito para a interação entre usuário e sistema. Da mesma forma, a interação pode ser entendida como a efetivação da interatividade, uma qualidade em potencial do sistema que se manifesta a partir da interação entre usuário e sistema.

Para que o usuário não se sinta desorientado durante a interação, ele precisa compreender como se deslocar entre os diferentes nós de informação oferecidos pela hipermídia. Para tal, é importante que o sistema de navegação seja facilmente perceptível, de forma que o usuário sintase confortável e seja estimulado a explorar livremente este espaço. Todas essas questões se

\footnotetext{
${ }^{1}$ De acordo com Garret (2010), o Design centrado no usuário visa criar experiências atraentes e eficientes para o usuário. Essa concepção pressupõe que o usuário seja considerado em todas as etapas envolvidas no desenvolvimeto de um sistema.

${ }^{2}$ Segundo o MEC (2012), tutores a distância atuam a partir da instituição, mediando o processo pedagógico junto a estudantes geograficamente distantes e tutores presenciais atendem os estudantes nos polos, em horários preestabelecidos.
} 
refletem diretamente na interface gráfica da hipermídia, elemento com o qual o usuário interage mais diretamente.

De acordo com Padovani e Moura (2008): "navegação consiste em um processo de movimentação entre os nós de um espaço informacional utilizando links ou ferramentas de auxílio à navegação". As autoras consideram que este conceito envolve tanto o aprendizado sintático àquele mais ligado ao nível operacional, focado no deslocamento, independente do conteúdo quanto ao aprendizado semântico - àquele relacionado ao nível funcional, que auxilia na integração entre diferentes informações; discussão esta que se mostra importante, principalmente, em hipermídias para aprendizagem.

\section{Usabilidade e avaliação}

Nielsen e Loranger (2007) conceituam usabilidade, como "um atributo de qualidade relacionado à facilidade de uso de algo". Assim, um sistema que impõe barreiras ou atrasos à interação gera insatisfação e desinteresse do usuário. Para Nielsen e Loranger (2007), a facilidade de uso referese à rapidez com que os usuários podem aprender a usar alguma coisa, a eficiência deles ao usála, o quanto lembram daquilo, seu grau de propensão de erros e o quanto gostam de utilizá-la. Para Cybis, Betiol e Faust (2007), a usabilidade está originalmente relacionada a ergonomia. A ergonomia pode ser entendida como uma qualidade "potencial" do sistema, quando elaborado de forma a adequar-se a seu usuário e a tarefa que este irá realizar. Já a usabilidade pode ser considerada uma qualidade "efetiva" da interação entre usuário e sistema ergonômico, atendendo de forma eficaz, eficiente e agradável os objetivos e expectativas desse usuário.

Em função da ampliação das aplicações e funcionalidades que os novos sistemas interativos estão oferecendo tem se tornado uma prática cada vez mais recorrente a avaliação da usabilidade de sistemas interativos a partir da experiência do usuário (PREECE, ROGERS e SHARP, 2005). Essa situação envolve uma avaliação da qualidade da interação, que visa identificar como o usuário se sente durante a interação com o sistema. Os métodos de avaliação com os usuários, que se caracterizam pela participação direta do usuário no processo de avaliação de usabilidade, dividem-se em métodos prospectivos e empíricos (DIAS, 2007).

Métodos prospectivos permitem ao avaliador de usabilidade conhecer as experiências, opiniões e preferências dos usuários ao utilizarem determinado sistema e podem ser usados em qualquer fase do projeto. Dentre eles, destacam-se os questionários e as entrevistas. As entrevistas são consideradas técnicas mais informais, que tornam mais complexa a aferição dos resultados e a validade de seus dados. Contudo, podem medir a ansiedade, a satisfação subjetiva e a percepção dos usuários com grande riqueza de detalhes.

\section{Hipermídias para aprendizagem de língua espanhola e o contexto da EAD}

O motivo pelo qual um aluno busca aprender uma língua estrangeira (LE) é de extrema importância para seu processo de aprendizagem. No caso de alunos de um curso de Licenciatura em língua estrangeira, por exemplo, esse motivo deve estar necessariamente relacionado ao ensino dessa língua. Para tal, esse aluno deve estar preparado para a prática docente atingindo níveis avançados de aprendizagem, dominando a língua em todas as suas habilidades comunicativas e linguísticas (NUNES e FONTANA, 2009).

De acordo com o Quadro Europeu Comum de Referências para as Línguas (2012) ${ }^{3}$, as habilidades comunicativas da língua envolvem as habilidades de compreensão leitora e auditiva, a expressão escrita e oral e a interação oral, cujo domínio é imprescindível para que um aprendiz torne-se um usuário competente da língua. No mesmo sentido, Leffa (2006) evidencia quatro habilidades básicas envolvidas na aprendizagem de língua estrangeira: ouvir, falar, ler e escrever.

Assim, segundo Leffa (2006), os materiais educacionais digitais voltados para língua estrangeira devem proporcionar ao aluno o desenvolvimento dessas quatro habilidades básicas, seja de

\footnotetext{
${ }^{3}$ O Quadro Europeu Comum de Referência para as Línguas: aprendizagem, ensino, avaliação é resultado de mais de dez anos de pesquisa conduzida por especialistas no campo da linguística aplicada e pedagogia, a partir de 41 EstadosMembros Conselho da Europa. Disponível em: <http://cvc.cervantes.es/ensenanza/biblioteca ele/marco/default.htm>. Acesso em: 05/03/12.
} 
forma individual ou integrada. Como exemplo têm-se uma atividade em que o aluno precise ouvir um diálogo, gravar sua pronúncia, ler o feedback fornecido pelo sistema e escrever um comentário. Dessa forma, por suas qualidades específicas como interatividade e hibridização de linguagens, da hipermídia se mostra como uma ferramenta valiosa para a aprendizagem de língua espanhola no contexto da EaD.

Um curso a distância é composto por diferentes equipes de trabalho que exercem funções específicas. Diferentes modelos de EaD resultam em variadas composições de equipes de trabalho. No entanto, de acordo com o MEC (2012), qualquer que seja a opção estabelecida, os recursos humanos devem configurar uma equipe multidisciplinar com funções de planejamento, implementação e gestão dos cursos a distância, onde três categorias profissionais, que devem estar em constante qualificação, são essenciais para uma oferta de qualidade:

- docentes;

- tutores;

- pessoal técnico-administrativo

Um sistema de tutoria para EaD de qualidade deve prever a atuação de profissionais que ofereçam tutoria a distância e presencial. Suas atividades desenvolvidas a distância e/ou presencialmente devem contribuir para o desenvolvimento dos processos de ensino e de aprendizagem e para o acompanhamento e avaliação do projeto pedagógico. Assim, os tutores a distância, que atuam a partir da instituição, tem como principal atribuição o esclarecimento de dúvidas através fóruns de discussão pela Internet, pelo telefone, participação em videoconferências, entre outros. Também precisam promover espaços de construção coletiva de conhecimento, selecionar material de apoio e sustentação teórica aos conteúdos e, frequentemente, participa dos processos avaliativos de ensino-aprendizagem, junto aos docentes.

Já os tutores presenciais, que atendem os estudantes nos polos em horários preestabelecidos, devem conhecer o projeto pedagógico do curso, o material didático e os conteúdos sob sua responsabilidade, para auxiliar os estudantes no desenvolvimento de suas atividades individuais e em grupo, fomentando o hábito da pesquisa, esclarecendo dúvidas sobre conteúdos específicos, bem como ao uso das tecnologias disponíveis. Participam de momentos presenciais obrigatórios, tais como avaliações, aulas práticas em laboratórios e estágios supervisionados, quando se aplicam. Devem manter-se em permanente comunicação tanto com os estudantes quanto com a equipe pedagógica do curso.

Em qualquer situação, os tutores precisam ser dinâmicos, ter visão crítica e global, capacidade para estimular a busca de conhecimento e habilidade com as novas tecnologias de comunicação e informação. Pelo exposto, é indispensável que as instituições desenvolvam planos de capacitação de seu corpo de tutores nas três dimensões: capacitação no domínio específico do conteúdo, capacitação em mídias de comunicação, e capacitação em fundamentos da $\mathrm{EaD}$ e no modelo de tutoria (MEC, 2012). É nesta perspectiva que este estudo se coloca, visando uma maior inserção do tutor nos processos de aprendizagem mediados pelas tecnologias.

\section{Procedimentos metodológicos: Projeto e avaliação da hipermídia Acércate al Diccionario}

O presente estudo foi estruturado a partir de três principais ações metodológicas, a saber: projeto e publicação da hipermídia Acércate al Diccionario no Ambiente Virtual de Ensino-Aprendizagem (AVEA) da disciplina de Língua Espanhola (LE) VII, avaliação desta hipermídia a partir de entrevistas com tutores; e tratamento, análise e síntese dos dados da avaliação. Na sequência essas etapas são detalhadas.

\section{Projeto e publicação da hipermídia}

Acércate al Diccionario foi elaborada no contexto da disciplina de Língua Espanhola (LE) VII, por uma equipe multidisciplinar que contava com um grupo do curso do Curso de Licenciatura em Letras-Espanhol na modalidade a distância UFSC, composto pela professora da disciplina, duas 
tutoras ${ }^{4}$ UFSC; e um grupo ligado ao Laboratório de Ambientes Hipermídia para Aprendizagem CCE/UFSC (Hiperlab), constituído por uma professora coordenadora, quatro designers e dois programadores. Além disso, contou com o trabalho de três locutores na elaboração dos áudios.

A hipermídia foi disponibilizada para alunos e tutores no Ambiente Virtual de Aprendizagem $^{5}$ da disciplina (LE VII) de 1o de abril a 26 de maio de 2011. Seu conteúdo tinha como foco o estudo sobre o uso pedagógico do dicionário e dividia-se em seis módulos: Introduccíon, Lexicografia pedagógica, La lexicografia, Actividades, Tipos y formatos de Diccionario e Entérate. Em seus módulos, os recursos midiáticos mais usados foram textos e imagens. Contudo, quatro deles também possuíam áudio, o qual podia ser bloqueado a qualquer momento, caso fosse de interesse do usuário.

Na sequência (ver Fig. 1), um esquema apresenta a arquitetura da informação da hipermídia, mostrando seus módulos de conteúdo, as informações nele contidas (até o primeiro nível hierárquico) e suas relações.

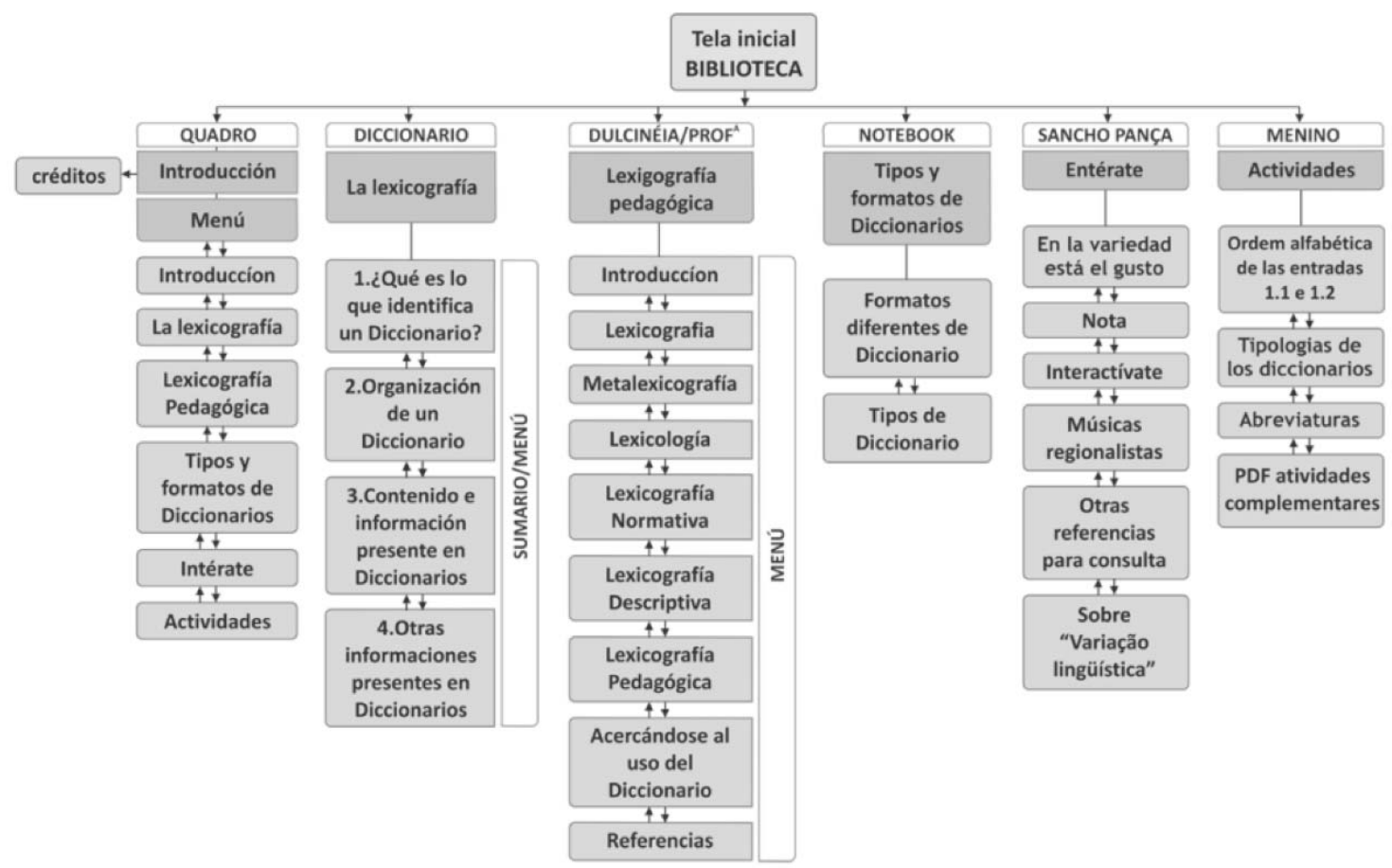

Fig. 1 - Esquema com a arquitetura da informação da hipermídia Acércate al Diccionario. Fonte: Autoras.

Acércate al Diccionario apresentava como metáfora visual principal uma biblioteca, que podia ser visualizada na tela inicial (Fig. 2). Dentro dela se encontravam objetos (livros, dicionários, notebook, aparelho de som, etc.) e quatro personagens que realizavam pequenos movimentos como virar o rosto para o lado, escrever, mover os braços, piscar, etc. Alguns dos personagens e objetos continham links para seus módulos de conteúdo, o que ficava evidente quando se passava o cursor do mouse sobre eles. Também era possível acessar seus módulos a partir do menu, presente na tela inicial, o qual apresentava uma lista com os títulos dos módulos e continha links para os mesmos.

\footnotetext{
${ }^{4}$ Sendo uma delas também designer instrucional do curso.

${ }^{5}$ O Ambiente Virtual de Ensino Aprendizagem do Curso de Licenciatura em Letras-Espanhol na modalidade a distância UFSC utilizava o aplicativo web gratuito Moodle, disponível em: <http://www.moodle.org.br/>.
} 


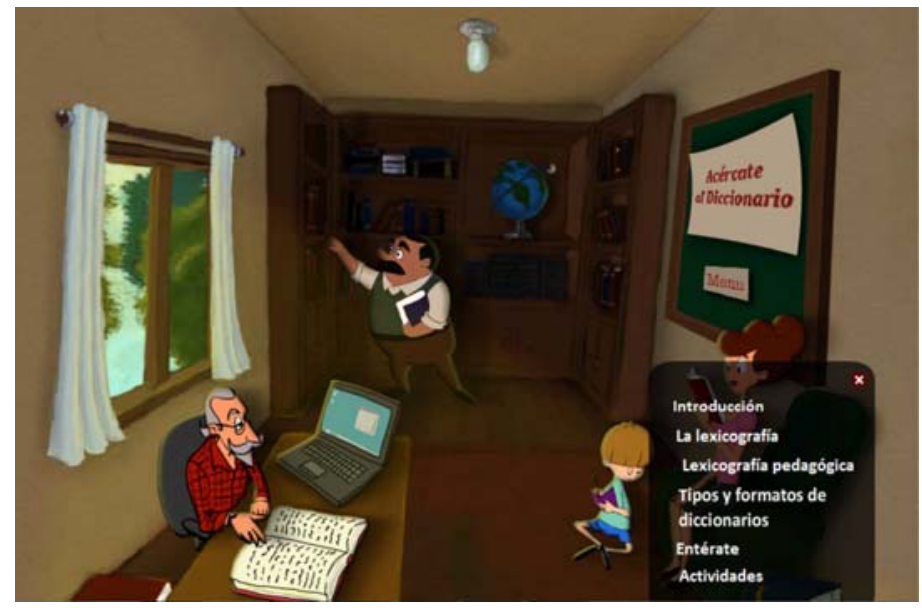

Fig. 2 - Tela inicial da hipermídia Acércate al Diccionario com o menu selecionado. Fonte: Arquivos do projeto Acércate al Diccionario - Hiperlab CCE/UFSC.

Dois de seus módulos também exploravam metáforas visuais. La lexicografía trazia a metáfora de um livro, cuja navegação poderia ocorrer a partir do menu ou "tela a tela", com o uso do recurso de flip, o qual simula o virar das páginas de um livro. Já o módulo Lexicografía pedagógica utilizava a metáfora de uma sala de aula, a partir das imagens de um quadro branco e de um anteparo para projeção multimídia, os quais eram alternados com o auxílio de recursos de animação, de acordo como conteúdo a ser acessado.

A seguir são apresentadas as telas iniciais de cada módulo de conteúdo da hipermídia (Fig. 3).
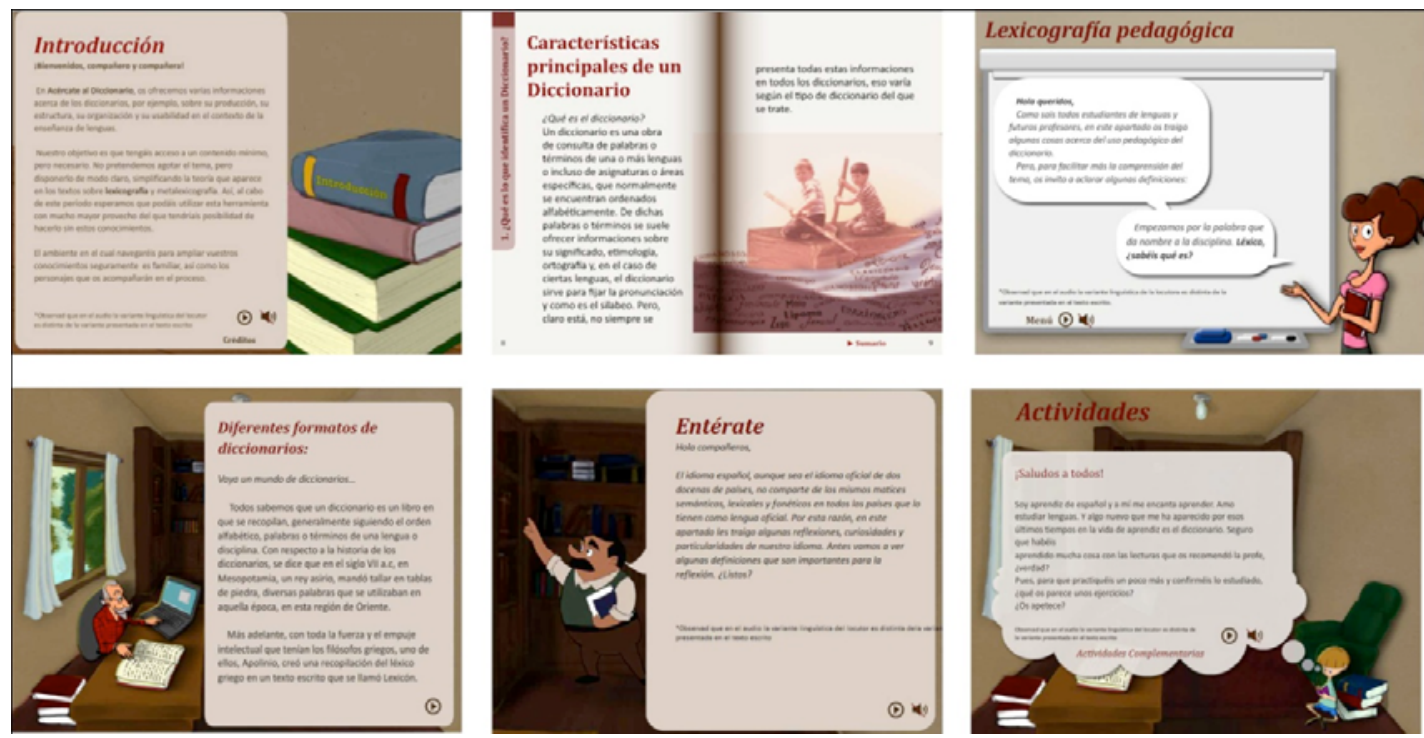

Fig. 3 - Telas iniciais dos módulos de conteúdo da hipermídia Acércate al Diccionario. Fonte: Arquivos do projeto Acércate al Diccionario - Hiperlab CCE/UFSC.

\section{Avaliação da hipermídia por usuários/tutores}

Após a disponibilização da hipermídia no AVEA do curso, foram realizadas entrevistas com tutores presencia e a distância. A primeira parte da entrevista exigia a lembrança sobre seu processo de interação e era composta por 10 perguntas (vide NUNES, 2012). A segunda parte da entrevista solicitava a busca de dois conteúdos específicos (Metalexicografía e Frases hechas, refranes y locuciones) no computador em que realizavam as entrevistas a distância; e encerrava com uma pergunta de caráter mais reflexivo. Os indicadores que nortearam o desenvolvimento das questões da entrevista com os tutores e configuraram-se como categorias de investigação foram: 
- número e local de acesso;

- explicitação dos objetivos de aprendizagem;

- clareza na apresentação dos conceitos/conteúdos;

- uso dos recursos midiáticos;

- legibilidade;

- consistência na apresentação visual das telas;

- organização dos conteúdos;

- facilidades e dificuldades durante a navegação;

- percurso de navegação e completude da busca;

- pré-requisitos para projetos de hipermídia no contexto do curso.

A partir de contatos feitos por e-mail, foram entrevistados três tutores presenciais (de um total de 10) e duas a distância ${ }^{6}$ (de um total de quatro), entre os dias 10 de maio e 29 de junho de 2011. Sua realização se deu, predominantemente ${ }^{7}$ à distância, através de um software de comunicação on-line (Skype) com uso de áudio. O tempo de duração de cada entrevista foi variável, entre 35 a 60 minutos, aproximadamente. Como forma de registro foram utilizadas gravação de áudio executada pelo próprio software de comunicação on-line ${ }^{8}$ - anotações e gravação das ações no usuário na interface no momento da busca (ZD Soft Screen).

Foi solicitado aos tutores que dispusessem no computador onde realizariam as entrevistas a distância um software de comunicação on-line (preferencialmente o Skype) e outro para a captação das ações na interface nos computadores (o ZD Soft Screen). Como grande parte deles já possuía o Skype ou tinha facilidade em consegui-lo, foram fornecidas orientações apenas para a instalação do software $Z D$ Soft Screen, compostas por um breve tutorial ${ }^{9}$ e o link para a instalação do mesmo.

\section{Apresentação e discussão dos dados}

Dos 14 tutores convidados, apenas cinco responderam aos contatos feitos por e-mail pela pesquisadora. Alguns deles manifestaram não ter disponibilidade, mesmo diante da flexibilidade de horários proposta pela pesquisadora. $\mathrm{O}$ fato de apenas cinco dos 14 tutores terem participado das entrevistas foi inesperado já que sua função dentro do curso é contribuir com o processo de ensino-aprendizagem dos alunos.

Em geral, os tutores entrevistados avaliaram positivamente a hipermídia. Para uma tutora presencial que atua em um dos polos do curso, sua dificuldade inicial de navegação estava essencialmente ligada à falta de familiaridade com tal tipo de sistema. Apenas um dos tutores presenciais considerou a hipermídia avaliada excessivamente complexa e sugeriu que fosse mais simples e objetiva, de modo a facilitar a interação dos alunos de EaD, que dedicam pouco tempo às atividades do curso.

Alguns tutores presenciais explicitaram que o fato de terem acesso à hipermídia ao mesmo tempo que os alunos, fez com que tivessem pouco conhecimento de determinados recursos e conteúdos da hipermídia durante o encontro presencial. Assim, ocorreu uma aprendizagem mútua com os alunos. Contudo, de forma geral os tutores entrevistados encontraram com relativa facilidade os conteúdos na busca realizada durante a entrevista. Na busca os menus e o recurso de bloqueio de áudio praticamente não foram utilizados.

\footnotetext{
${ }^{6}$ As duas tutoras a distância fizeram parte da equipe multidisciplinar envolvida na elaboração da hipermídia. Assim, suas respostas traziam tanto uma visão de membro da equipe, relativa ao processo, como de usuária, em relação ao produto final.

${ }^{7}$ Apenas uma tutora a distância foi entrevistada presencialmente, em função de sua disponibilidade.

${ }^{8}$ Exceto no caso da entrevista realizada presencialmente que utilizou um software específico para a gravação de áudio.

${ }^{9}$ Elaborado pela pesquisadora com o auxílio do software ZD Soft Screen.
} 
O quadro a seguir (Quadro 1) apresenta uma síntese do percurso de navegação dos tutores entrevistados, que enfatiza a ordem dos módulos acessados; bem como o uso do menu da tela inicial. Os módulos referenciados pelo nome foram aqueles acessados a partir do menu da tela inicial. Aqueles citados pelo nome do personagem/objeto correspondente foram acessados a partir da ilustração da tela inicial da hipermídia. Já os módulos com nome em cinza foram abertos pelos tutores, mas não explorados.

Tutora 1: menu $\rightarrow$ Introduccion $\rightarrow$ livro $\rightarrow$ notebook $\rightarrow$ Sancho $\rightarrow$ professora

Tutora 2: livro $\rightarrow$ menino $\rightarrow$ Sancho $\rightarrow$ professora

Tutor 3: professora $\rightarrow$ Sancho $\rightarrow$ menino

Tutora 4: livro $\rightarrow$ notebook $\rightarrow$ professora $\rightarrow$ Sancho $\rightarrow$ notebook $\rightarrow$ livro

Tutora 5: professora $\rightarrow$ Sancho $\rightarrow$ notebook $\rightarrow$ livro $\rightarrow$ livro

Quadro 1 - Síntese do percurso de navegação dos tutores na busca de conteúdos realizada durante as entrevistas. Fonte: Autoras.

As tutoras a distância foram mais críticas e detalhistas na avaliação da hipermídia do que a maior parte dos tutores presencias. Assim, identificaram problemas de legibilidade e de clareza dos conteúdos; bem como identificaram a necessidade de oferta de outras possibilidades de navegação. Possivelmente, essa situação se deva ao fato destas terem participado do processo de elaboração da hipermídia obtendo um maior conhecimento da mesma.

A seguir apresenta-se um quadro que sintetiza os principais pontos coletados nas entrevistas com os tutores, de acordo com as categorias de investigação propostas (Quadro 2).

\begin{tabular}{|c|c|}
\hline Categorias de investigação & $\begin{array}{l}\text { Principais questões identificadas nas entrevistas com os } \\
\text { tutores }\end{array}$ \\
\hline Número de acessos & $\begin{array}{l}\text { - A maior parte dos tutores presenciais acessou a hipermídia de } 3 \text { e } \\
4 \text { vezes. As tutoras a distância acessaram a hipermídia mais de } 30 \\
\text { vezes como desenvolvedoras e usuárias; } \\
\text { - Para os tutores presenciais, o acesso à hipermídia estava } \\
\text { essencialmente ligado ao suporte aos alunos; } \\
\text { - A disponibilização da hipermídia para alunos e tutores ao mesmo } \\
\text { tempo gerou uma aprendizagem mútua; } \\
\text { - Três tutores acessaram mais de } 15 \text { vezes. }\end{array}$ \\
\hline $\begin{array}{l}\text { Explicitação dos objetivos de } \\
\text { aprendizagem }\end{array}$ & $\begin{array}{l}\text { - Os objetivos estavam claramente explícitos para quase todos os } \\
\text { tutores; } \\
\text { - Foi salientada a importância da mediação do tutor na reiteração } \\
\text { dos objetivos de aprendizagem. }\end{array}$ \\
\hline $\begin{array}{l}\text { Apresentação dos conceitos/ } \\
\text { conteúdos }\end{array}$ & $\begin{array}{l}\text { - Para os tutores presenciais os conceitos estavam suficientemente } \\
\text { claros e para as a distância, ficariam mais explícitos se os } \\
\text { conteúdos fossem mais objetivos e sucintos. }\end{array}$ \\
\hline Recursos midiáticos & $\begin{array}{l}\text { - O uso de recursos na hipermídia foi considerado adequado por } \\
\text { todos os tutores. }\end{array}$ \\
\hline Legibilidade & $\begin{array}{l}\text { - Os tutores presenciais consideraram legíveis as informações } \\
\text { textuais da hipermídia. As tutoras a distância apontaram problemas } \\
\text { de tamanho de fonte e espaçamento entrelinhas em alguns trechos. }\end{array}$ \\
\hline $\begin{array}{l}\text { Consistência na apresentação } \\
\text { visual das telas }\end{array}$ & $\begin{array}{l}\text { - Todos os tutores identificaram consistência visual entre as telas da } \\
\text { hipermídia. }\end{array}$ \\
\hline Organização dos conteúdos & $\begin{array}{l}\text { - Considerada adequada para a maioria dos tutores; } \\
\text { - Foi citado que a ausência de link no personagem sentado tornou a } \\
\text { navegação confusa; } \\
\text { - Ressalva para o elevado número de links externos. }\end{array}$ \\
\hline
\end{tabular}




\begin{tabular}{|l|l|}
\hline $\begin{array}{l}\text { Facilidades encontradas durante a } \\
\text { navegação }\end{array}$ & $\begin{array}{l}\text { - A navegação pelo sistema foi considerada fácil por quase todos os } \\
\text { tutores; } \\
\text { - Alguns tutores citaram La lexicografia e Lexicografía pedagógica } \\
\text { como módulos mais fáceis de navegar. }\end{array}$ \\
\hline $\begin{array}{l}\text { Dificuldades encontradas durante a } \\
\text { navegação }\end{array}$ & $\begin{array}{l}\text { - A navegação da hipermídia restrita à tela inicial. As tutoras a } \\
\text { distância sugeriram que fosse possível navegar dos módulos para a } \\
\text { tela inicial e das telas dos links externos para as telas dos módulos, } \\
\text { sem mudar de aba de navegação; } \\
\text { - Alguns tutores citaram La lexicografia e Entérate como módulos } \\
\text { mais difíceis de navegar. }\end{array}$ \\
\hline $\begin{array}{l}\text { Percurso de navegação e } \\
\text { completude da busca }\end{array}$ & $\begin{array}{l}\text { - Quatro tutores encontraram os dois conteúdos e um encontrou } \\
\text { apenas Metalexicografía; } \\
- \text { Todos os tutores tiveram relativa facilidade para encontrar os } \\
\text { conteúdos durante a busca; } \\
\text { - Durante a busca, raramente os tutores utilizaram os menus e o } \\
\text { bloqueio de áudio. }\end{array}$ \\
\hline $\begin{array}{l}\text { Pré-requisitos para projetos de } \\
\text { hipermídia no contexto do curso }\end{array}$ & $\begin{array}{l}\text { - Muitos dos pré-requisitos citados estavam ligados ao uso de } \\
\text { áudio, em atividades que exercitassem a pronúncia da língua } \\
\text { espanhola e como forma de interação entre sistema; } \\
- \text { Outros pré-requisitos citados foram: busca por palavra-chave, } \\
\text { orientação para a navegação e legendas com título e a descrição } \\
\text { dos conteúdos contidos nos links. }\end{array}$ \\
\hline
\end{tabular}

Quadro 1 - Síntese das principais questões levantadas nas entrevistas realizadas com os tutores. Fonte: Autoras.

Quanto aos pré-requisitos para projetos de hipermídia no contexto do curso, o elemento da hipermídia mais citado pelos tutores foi o áudio, por se tratar de um curso de língua estrangeira, no qual os alunos precisam dominar habilidades orais. Neste sentido, foi sugerida a exploração de atividades orais que exercitassem a pronúncia da língua espanhola, questão citada pelos tutores como sendo uma das maiores dificuldade dos alunos, gerando insegurança na prática docente. Além disso, foi sugerida a exploração do áudio como forma de interação entre o sistema e o usuário como, por exemplo, no diálogo dos personagens. Segundo elas, esse diálogo poderia, inclusive, fornecer orientações sobre a navegação.

Além disso, foi sugerido o uso de um recurso de busca por palavra-chave e de legendas com título e descrição dos conteúdos contidos em cada link. Também foram citadas outras questões mais diretamente relacionadas com a hipermídia avaliada como a presença de um módulo com conteúdo gramatical que auxiliasse a realização das atividades e a disponibilização de conteúdos menos densos e textos autorais. Contudo, tendo em vista a experiência docente das tutoras (no curso e em outros contextos), as sugestões poderiam ter sido mais numerosas e abrangentes, incluindo aspectos como tipo de linguagem oral e visual a serem utilizados, recursos midiáticos a serem explorados, estratégias e ferramentas de navegação, dentre outros.

\section{Considerações finais}

A partir desse estudo foi possível identificar que, de forma geral, os tutores avaliaram positivamente a hipermídia Acércate al Diccionario, considerando que seus objetivos de aprendizagem, conceitos/conteúdos e sua organização foram apresentados de forma clara. A maior parte deles não encontrou dificuldade durante o processo de interação apesar de terem acessado a hipermídia ao mesmo tempo em que os alunos, o que foi possível verificar também durante a busca de conteúdos. Contudo, foram apontadas algumas questões que merecem maior atenção, tais como a ausência de link no personagem sentado, infringindo a consistência e tornando a navegação confusa; o elevado número de links externos com a abertura de novas janelas de navegação; e a necessidade de retornar a tela principal para acessar os módulos de conteúdo.

A ênfase dada pelos tutores à exploração do áudio para exercício da oralidade da língua, especialmente na questão sobre pré-requisitos para futuros projetos, reforça sua importância na elaboração de hipermídias para aprendizagem de língua espanhola. Contudo, os resultados 
evidenciam que tal situação não dispensa a utilização de recursos como o texto, que tem um papel fundamental na aquisição dos conhecimentos teóricos e da habilidade escrita; bem como de imagens estáticas e em movimento, que contribuem para a compreensão e memorização dos conteúdos.

Algumas das sugestões e soluções apontadas pelos tutores como a manutenção do menu em todas as telas da hipermídia, a presença de um recurso de busca por palavras-chave e de uma orientação para a navegação foram de grande importância, porém abaixo da expectativa desta pesquisa em termos numéricos, visto que tratam-se de tutores experientes. Essa situação se verifica também quanto ao reduzido número de tutores participantes da avaliação, cuja participação no processo de aprendizagem é de grande importância, o que limita a gama de questões apontadas e a confiabilidade da avaliação.

Esses resultados apontam algumas das características do processo de interação entre tutores do curso de Licenciatura em Letras-Espanhol na modalidade a distância UFSC e uma hipermídia para aprendizagem, os quais espera-se que possam contribuir com o desenvolvimento de futuros projetos no âmbito do curso.

\section{Referências}

DIAS, Cláudia. Usabilidade na web: Criando portais mais acessíveis. $2^{\underline{a}}$ ed. Rio de Janeiro: Alta Books, 2007.

FILATRO, Andrea. Design instrucional na prática. São Paulo: Pearson Education do Brasil, 2008.

FLOR, Carla da Silva et al. A hipermídia como ferramenta de aprendizagem na sociedade do conhecimento. In: $4^{\circ}$ Congresso Nacional de Ambientes Hipermídia para Aprendizagem (Conahpa), 2009, Florianópolis. Anais...Florianópolis: UFSC/UCPel, 2009.

CYBIS, Walter; BETIOL, Adriana Holtz; FAUST, Richard. Ergonomia e Usabilidade: Conhecimentos, métodos e aplicações. São Paulo: Novatec, 2007.

LEFFA, Vilson J. . A aprendizagem de línguas mediada por computador. In: Vilson J. Leffa. (Org.). Pesquisa em lingüística Aplicada: temas e métodos. Pelotas: Educat, 2006, p. 11-36.

LIMA-MARQUES, Mamed e CAVALCANTE, Gustavo Vasconcellos. Hipermídia e Rede Complexa. In: ULBRICHT, Vania Ribas; PEREIRA, Alice Therezinha Cybis (Orgs). Hipermídia: desafios da atualidade. Florianópolis: Pandion, 2009, p. 156-172.

MINISTÉRIO DA EDUCAÇÃO (MEC/SEED). Referenciais de qualidade para educação superior a distância. Disponível em: <http://portal.mec.gov.br/seed/arquivos/pdf/legislacao/refead1.pdf>. Acesso em: 10/12/2012.

NIELSEN, Jakob; LORANGER, Hoa. Usabilidade na Web. Rio de Janeiro (RJ): Elsevier, 2007.

NUNES, Elton Vergara; FONTANA, Marcus Vinícius Liessem. A interação oral em ambiente virtual de aprendizagem em curso de Espanhol na modalidade a distância. In: $4^{\circ}$ Congresso Nacional de Ambientes Hipermídia para Aprendizagem (Conahpa), 2009, Florianópolis.

Anais...Florianópolis: UFSC/UCPel, 2009.

NUNES, Juliane Vargas. Orientações focadas no desenvolvimento de hipermídias para aprendizagem de língua espanhola na EaD. 150p. Dissertação (Mestrado) - Universidade Federal de Santa Catarina, Centro de Comunicação e Expressão, Programa de PósGraduação em Design e Expressão Gráfica. 2012.

PADOVANI, Stephania. Usabilidade de sistemas de navegação em hipermídia. In: 3ํㅡㄴ Conahpa, 2008, São Paulo/SP. 3 Congresso Nacional de Ambientes Hipermídia para Aprendizagem, 2008.

PADOVANI, Stephania; MOURA, Dinara. Navegação em Hipermídia: uma abordagem centrada no usuário. Rio de Janeiro: Ciência Moderna Ltda., 2008.

PREECE, Jennifer; ROGERS, Yvonne; SHARP, Helen. Design de interação: Além da interação humano-computador. Porto Alegre: Bookman, 2005. 
SANTAELLA, Lúcia. Navegar no Ciberespaço: o perfil cognitivo do leitor imersivo. São Paulo: Palus, 2004.

ULBRICHT, Vania Ribas et al. Design de hipermídia: proposta metodológica. In: 3o Conahpa, 2008, São Paulo/SP. 3ํㅡㄹ Congresso Nacional de Ambientes Hipermídia para Aprendizagem, 2008.

\section{Sobre as autoras}

Juliane Vargas Nunes, Ms. pelo Pós-Design UFSC: Design de Hipermídia. Desenvolve pesquisas nas áreas de Design de Hipermídia e usabilidade em aplicativos para dispositivos móveis.

<julivn@gmail.com>

Berenice Santos Gonçalves, Dra. Professora do curso de Graduação e Pós Graduação em Design da UFSC. Desenvolve e orienta pesquisas nas áreas de Hipermídia e Multimídia editorial. Participa do Laboratório de Ambientes Hipermídia para Aprendizagem - HIPERLAB/EGR/CCE/UFSC.

$<$ berenice@cce.ufsc.br> 